\title{
The reality of learners' achievements with IT in the classroom
}

\author{
David C. Johnson
}

Shell Professor of Mathematics Education

King's College, University of London, United Kingdom

\begin{abstract}
Is there a link between surveys of resources and use and the research on pupil's achievements using IT? Although evidence of an increasing level of provision, and reports on learning with IT indicate the potential, there is still the question of the reality of classrooms. The UK ImpacT research indicates that within 'computer using' classrooms the benefits can be positive. However, these benefits are dependent upon the nature of the experiences and aspects of teaching style and classroom management. Even with a high level of commitment to the acquisition of equipment, the present situation is still deficient in terms of pupil and teacher access and teacher support.
\end{abstract}

Keywords: information technology, learning, research, teaching methods

\section{INTRODUCTION}

".. notebook computers are producing positive results in the school science laboratory." (Times Educational Supplement, "IT Review", 7 January, 1994, p. 26)

"... this month's (UK) technology in education (conference) clearly demonstrated how quickly IT has become part of the fabric of most schools and colleges." (Times Educational Supplement, "Computers/IT", 21 January, 1994, p.17) 


\section{Integrating information technology into education}

The first editorial above goes on to note that students were "confidently using the data-logging equipment", and further that word processing and spreadsheets were also "proving valuable". And in the second, a number of recent commercial developments were described, along with statements suggesting, for example, a "dramatic growth of CD-ROM in education" and exciting developments in the use of interactive optical disc systems. Very little, however, was said about the actual activities or achievements of the learners, their expectations and behaviour in these integrated informatics environments, nor where one might readily observe this phenomenon. While it does seem clear that developments in hardware and software offer truly exciting potential, what do we know about the reality of classrooms? Is this integration really as common-place as suggested in the press? Further, does the 'integration', if it is really taking place on any large scale, provide benefits beyond training in the use of the technology?

There exists considerable evidence related to the theme of learners in an integrated IT environment, which has been generated through a range of data collection activities. One main source are the large scale surveys of availability of resources, for example numbers of machines and pupil/machine ratios, and aspects of access and use in school subjects, often presented as percentages of total computer use distributed across subjects such as maths, science, native language, etc.. In the UK such work has been carried out on a regular basis by the Department for Education (see [1], [2], and [3]). At the international level we have the multi-national IEA Computers in Education Study [4], and, of particular relevance to this paper, Anderson's [5a] report on the US component of this work. Anderson reports on a large scale survey (over 69,000 pupils, aged 10,13, and 16, in 2,500 schools) conducted in 1992, a follow-up to a similar study conducted in 1989 . The report provides information on percentages of teachers in "computer-using schools" who use computers in class "on at least several occasions during the year", typically around 50\%. The schools also had a pupil/computer ratio of about $7 / 1$, and note is made of the fact that since 1989, U.S. schools have increased their inventory of computer units by as much as $50 \%$. In making international comparisons, Anderson states that "in ... peripherals and networks, the US has at the very least comparable and often larger inventories than the other countries (in the IEA survey)" p. 27.

The US study also placed emphasis in the research upon using computers in learning different subjects such as science, geography, languages. "In the U.S., about half of school computer time is spent on learning about computers and the other half on learning other subjects with 
the help of computers" (p. xvii). But what does this "learning other subjects" really mean? Some aspects of this question are discussed by Lundmark in the chapter "pupils' opportunity to learn with computers" [5b], but the evidence reported is primarily that of "counts" of responses to items in the survey questionnaire as opposed to actual observations of classes and pupil assessments. An important consideration in the discussion is the fact that pupils were counted as a "substantial user" of IT, if they used software six or more times in the school year, i.e. six or more times in a period of 150 school days. In her conclusions, Lundmark notes that:

"The question of how far computer instruction has been integrated across the school subjects curriculum is noteworthy. A little more than one-fourth of all US students say they used computers in none of the traditional subjects (included in the survey) and a little more than one-fourth say they used computers in only one of those ... subjects during the year. ... it seems that the use of computers as instructional tools has not advanced very far across the curriculum." p. 70.

A further source of evidence for discussing learners and IT in school subjects, are the numerous studies conducted in different educational contexts, for example, multimedia learning environments or aspects of group work in classrooms, or studies which focus on the effects of IT on pupils' learning within a specific conceptual domain in a curriculum area. Niemiec and Walburg [6] report on results from over 250 studies on the effects of IT on pupils' learning of particular skills and concepts, with the overall results generally supportive of the experience.

Evidence can also be found in books, monographs and conference proceedings, which summarise and synthesize the research and theoretical perspective supporting classroom activity linked to a particular type of use such as simulations, or the role of powerful generic software tools $[7,8]$. Conference proceedings often include sub-themes which provide some degree of synthesis, either within or across some classification [9].

As already indicated, the evidence from these, and other sources (e.g., the practical materials produced for teachers) is generally supportive of the role of IT. Some research evidence links the surveys of access and use with individual studies with their focus on classroom activity in a well-defined subject context; other reports synthesize work in support of a particular type of activity addressing issues of teaching and learning in the wider context of 'real' classrooms. Such evidence is, at best, limited. What can we say about the impact of IT on teachers and pupils activities and achievements, across subjects and over time in the world of "typical" 


\section{Integrating information technology into education}

schools? Are results only possible in restricted and highly supported (both in terms of people and resources) contexts, as typified by those described in many of the individual studies reported in the literature? Is it still a case of "we know what might be achieved, but are not in a position to reach this potential in most schools?"

\section{THE IMPACT RESEARCH (ENGLAND AND WALES)}

The UK ImpacT study [10a]; "an evaluation of the impact of information technology (IT) on children's achievements in primary and secondary schools", was carried out in the period January 1989 - December 1991. While status data dealing with resourcing and use comparable to some aspects of the US study were collected, a main focus of the research was on pupils' achievements and classroom activity involving IT. Assessments and monitoring were conducted in the subject areas of mathematics, science, geography, and English, over a period of two years with pupils in the age ranges 8-10, 12-14, and 14-16. The sample involved over 2300 pupils from 87 classes in 19 Local Education Authorities in England and Wales.

The ImpacT work both extends and links aspects of the research literature base in this area to include longitudinal effects within school subjects, cross subject considerations of general aspects of classroom use of IT, and the provision and use of hardware and software resources. These were integrated to address a range of issues encompassing learning, pedagogy, and policies. The ImpacT results from the component parts were linked to enable the research team to address three main questions:

- Pupils' Learning: did IT make a contribution?

- Pedagogy and Practice: what can we say about the planning and practice of teaching to incorporate IT?

- Schools' Organization: what were the demands of IT on the schools?

The focus of the remaining portion of this paper is on the first question, which represents one main component in considering learner's outcomes, within an integrated informatics environment, with selected findings related to the second question used to inform or extend some aspects of the discussion.

\section{Methodology}

One important feature in the ImpacT research design was the inclusion of pupils from matched pairs of classes. One of each pair was identified as 
making regular use of IT, designated HiIT where the teacher was an experienced user of IT and had plans for regular use during the period of the research. The initial confirmation of this designation was a non-trivial undertaking. The HiIT class was then matched with another class for which the teacher had no plans for using IT, making low, or no, use of IT, and thus designated LoIT. LoIT class teachers in particular were also nominated for their good teaching and curriculum delivery; it was not merely a case of finding volunteers. The pupils divided into a matrix of 12 cells, the three age groups crossed with the four curriculum areas. The sample was used in a framework for data collection which had three substantial parts:

- An assessment of pupils' achievement, through the administration of specially designed subject focussed assessments. These were supplemented by eight topic specific mini-studies in some pairs and also some HiIT only classes, and a final test for IT concepts and skills. Statistical comparisons of test performance were adjusted through the use of general ability assessments.

- Five in-depth longitudinal case studies in HilT classes, focussed on classroom processes and pupil interactions. Classrooms were observed, pupils and teachers were interviewed and documentary evidence was gathered to provide illumination on classroom realities. Qualitative analysis was based on those themes and issues that emerged from the data.

- IT resourcing and use was monitored throughout by the regular returns of questionnaires and data sheets from the teachers and pupils in each class. Hardware and software provision, pupils' IT use in ImpacT subject and across all subjects, and pupils' extra-mural use were analysed descriptively by classes, age cohorts and school subjects.

Further details on the research design and methodology are given in the full report [10b] and a recent paper [11].

\section{ImpacT: Results and discussion}

Within the limitations of the study [10c], the answer to the question of "the contribution of IT use to learning" was yes, IT did make a difference, but the contribution was not consistent across school subjects or age bands. The global results in support of this response were from the main field study subject reasoning assessments; post-tests administered twice for each subject. These were also supported by the results of the 'topic specific' mini-studies. An overall summary of the HiIT and LoIT group outcomes, subject reasoning and mini-studies, is given in the table below. 
In the case of subject reasoning, these represent combined effects for both assessments in each subject age band.

\begin{tabular}{|c|c|c|c|c|c|c|c|c|}
\hline \multirow{2}{*}{$\begin{array}{c}\text { Subject } \\
\text { Age }\end{array}$} & \multicolumn{2}{|c|}{ Mathematics } & \multicolumn{2}{|c|}{ Science } & \multicolumn{2}{|c|}{ Geography } & \multicolumn{2}{|c|}{ English } \\
\hline & $\begin{array}{l}\text { Subj. } \\
\text { Reas. }\end{array}$ & $\begin{array}{l}\text { Mini } \\
\text { Study }\end{array}$ & $\begin{array}{l}\text { Subj. } \\
\text { Reas. }\end{array}$ & $\begin{array}{l}\text { Mini } \\
\text { Study }\end{array}$ & $\begin{array}{l}\text { Subj. } \\
\text { Reas. }\end{array}$ & $\begin{array}{l}\text { Mini } \\
\text { Study }\end{array}$ & $\begin{array}{l}\text { Subj. } \\
\text { Reas. }\end{array}$ & $\begin{array}{l}\text { Mini } \\
\text { Study }\end{array}$ \\
\hline 8-10 & pos. $^{a}$ & $\begin{array}{c}\text { no } \\
\text { study }\end{array}$ & neg. & incon. ${ }^{c}$ & \multicolumn{2}{|c|}{$\begin{array}{c}\text { age group was } \\
\text { not included }\end{array}$} & pos. $^{d}$ & pos. \\
\hline $12-14$ & incon. & pos. & incon. & $\begin{array}{c}\text { no } \\
\text { study }\end{array}$ & incon. & $\begin{array}{c}\text { no } \\
\text { study }\end{array}$ & incon. & incon. $^{e}$ \\
\hline $14-16$ & pos. & $\begin{array}{c}\text { no } \\
\text { study }\end{array}$ & incon. & $\begin{array}{l}\text { pos. }^{\mathbf{e}} \\
\text { incon. }\end{array}$ & pos. & pos. & \multicolumn{2}{|c|}{$\begin{array}{l}\text { insufficient data } \\
\text { for analysis }\end{array}$} \\
\hline nos & (non & ult fav & diff & $\begin{array}{ll}\text { es. } & \text { d. }\end{array}$ & g. - n & tive 1 & $\begin{array}{l}\text { it, favo } \\
\text { partial }\end{array}$ & ced LoIT \\
\hline
\end{tabular}

Table 1: Summary of ImpacT Results: Field Study Reasoning-in-Subject Tests and Mini-studies

The major focus of the subject reasoning assessments was on higher order processes and thinking deemed appropriate to each subject; for example, relational thinking in mathematics; formulating hypotheses and designing experiments in science; drawing inferences from map, graphical and photographic information in geography; and aspects of content and cohesion/coherence in pupils' writing in English.

When these results were probed at the level of classes it was the case that the results from a small number of the HiIT classes provided the main evidence for the findings reported in Table 1. Access and use in these classes suggested there may well be some minimum threshold of IT use for the impact to be detected. The results from the US survey and the Impac $T$ resources and use data, suggest such access is not a common phenomena.

In terms of topic specific learning outcomes, five of the eight mini-studies provided evidence in support of the affirmation that IT use contributed to learning. This is consistent with the results from 'topic specific' research reported in the literature. However, in the case of the ImpacT research, the results also indicated that the contribution was in terms of higher level processes or thinking. For example, in the mathematics mini-study on angles the two classes were studying the same materials, with the pupils in the HiIT class also working with the programming language Logo. The HiIT class achieved significantly higher results, with the main contribution being to the higher level 
processes, i.e. application of the concepts and relationships [12]. Similar contributions were noted for:

- a HiIT-LoIT science mini-study dealing with relationships between elements where the HilT class used a database of chemical elements;

- a HiIT only geography mini-study 'indicators of development' in which the pupils were observed while using the world countries database PCGlobe;

- two mini-studies in English, which involved aspects of pupils' writing using word processing (one a HiIT-LoIT comparison and the second HilT only).

While one of the science mini-studies indicated a contribution from the use of IT, this was offset by the failure to detect any differences in the other two mini-studies and the consistent negative or inconclusive results for the science subject reasoning assessments. However, it was also the case that science represented the most difficult area for the identification of HiIT classes. Computer use in science was generally low when compared with the use in the other ImpacT HiIT classes. While the relative percentages of IT use at the international level also support this finding, it still remains a paradox in that much work has been done in hardware and software development to support learning in science; how does one explain this apparent contradiction?

As indicated in the research methodology, the main focus of the case study research was on classroom processes. While the data collection was rigourous and detailed, the analyses were designed to provide exemplification rather than generalisations, and as such serve to illuminate rather than explain the achievement outcomes. Selected observations from the case study classes suggest some important considerations associated with pupils' use of IT:

- computers were found to be good motivators which heightened pupils' interest and enjoyment and were also seen to have a positive effect upon the status of the subject;

- computers aided concentration by focussing pupils' attention on the work in hand and as a result some pupils and teachers believed that the standard of work produced was of a higher quality than it would have been otherwise;

- opportunities to work in an open-ended way enabled pupils to become involved in more complex and challenging learning situations beyond that typically experienced. 
Further, some of the failures to detect any contributions through the use of IT may be attributed to some of the problems encountered by pupils in the case study classes:

- difficulties in using a particular software package;

- inability to work effectively in a collaborative environment.

The link of achievement results to teacher style or planning provided some further insights in terms of pedagogy and practice:

- The answer to the question regarding the planning and practice of teachers mainly involved a consideration of classroom management and organisation and teaching styles along with aspects of hardware and software availability and use. The results from the case studies, mini-studies, and aspects of the field study, indicated quite clearly that any contribution was dependent upon a range of factors, the most important being that of the role of the teacher.

- Teachers' responsibilities were found to demand careful attention to organisation and management, in particular the effective use of collaborative or group work. Further, effective use of IT represented substantial demands in terms of knowledge and understanding of, and familiarisation with, a variety of software in order to integrate the activity, in philosophical and pedagogical terms, within a larger scheme of work.

- The use of more general purpose software, for example spreadsheets, databases, and programming, placed additional demands on the teacher, beyond that of becoming familiar with the use of the more complex software, to include more reflection on the nature of their subject and the potential role of such software in enhancing processes and understanding of 'big' ideas or relationships.

These points are quite consistent with reports on research cited earlier in this paper, in particular those works which attempt to synthesize results across a wider domain of studies. On the other hand, if we are truly working towards an integrated informatics learning environment for all, the integration of findings and the linking of such evidence to the world of 'real' classrooms demands attention to a multitude of issues. Two issues of importance here are those of access and teacher support. 


\section{CONCLUSIONS}

Research, including that from the ImpacT study described above, has confirmed the potential for significant contributions of IT to pupils' learning. It is proposed here that any consideration of the notion of "learner's expectations and behaviours in an integrated informatics environment" is of course firstly dependent upon planned experiences being available through the provision of both resources and opportunities to access and use the resources to engage in challenging tasks. As indicated above, the role of teachers is crucial to this endeavour, and this in turn is dependent on their perceptions as to the benefits from such opportunities and their ability to take action. Of particular importance are their abilities linked to teaching styles and classroom management, along with, of course, those widely acknowledged capabilities of rapport, insight, and capacity for work. Attention is directed here to two recent insightful reports on case studies of teachers who have effectively integrated computing into their instructional processes [10d], [13].

While the role of the teacher is accepted as of paramount importance, it is also the case that all involved, teachers and pupils, need "ready" access to equipment. What does this really mean? It is accepted that government, local education authorities and schools have made efforts towards increasing the numbers of machines available to pupils (decreasing the pupil/machine ratio), and, for many countries, there have been some dramatic changes. However, while Anderson recommends a ratio of $5 / 1$ by 1995 [5a], and such might seem encouraging, I would suggest that even this is far from adequate. A recent computer manufacturer newsletter, Acorn Arc, Autumn 1993, notes a goal of "one micro per child" p.18, but my own suggestion is that "schools, as business, should have more computers than people".

This is not to say we need fewer teachers, but rather that the resources available should be such that teachers and pupils each have their own computer, and the provision of other resources, such as electronic communication, multi-media or CD-ROM and interactive optical disk, should be of an order to facilitate the full range of potential activities in teaching and learning supported with IT. The goal of maximising the use of available equipment, so that machines should not be idle during the day, for reasons of cost, is inappropriate in contexts which look to optimising the productivity of people.

With this in mind, I end this paper with the question; "How would you feel if you had to book time on your machine?" I would be truly lost without the 'Apple on my desk' to use when, and if, I feel the need. The 
idea that I should share or book time, because the technology is not being used throughout the day, would represent a real intrusion. What does this say about "learner's expectations and behaviours"?

\section{REFERENCES}

1. D.E.S. (1986) Results of the Survey of Microcomputers in Schools. Statistical Bulletin 18/86. London: D.E.S.

2. D.E.S. (1989) Results of the Survey of Information Technology in Schools. Statistical Bulletin 10/89. London: D.E.S.

3. D.E.S. (1991) Results of the Survey of Information Technology in Schools. Statistical Bulletin 11/91. London: D.E.S.

4. Pelgrum, W.J., and Plomp, T. (1991) The Use of Computers in Education Worldwide. Results from the IEA Computers in Education Survey in 19 Education systems. Oxford (England): Pergamon Press.

5a, b. Anderson, R.E. (Ed.) (1993) Computers in American Schools 1992: An Overview. A National Report from the International IEA Computers in Education Study. Minneapolis (Minnesota): University of Minnesota (Social Sciences).

5b. Lundmark, V.A., Opportunity to Learn with Computers Chapter 5, 55-70.

6. Niemiec, R.P., and Walburg, H.J. (1992) The Effects of Computers on Learning. International Journal of Educational Research 17(1).

7. Hoyles, C., and Noss, R. (Eds.) (1992) Learning Mathematics and Logo. Cambridge (Massachusetts): The MIT Press. Note the focus on the learner in the papers by Kynigos, The Turtle Metaphor as a Tool for children's Geometry, 97-126, and Hoyles and Noss, Looking Back and Looking Forward, 431-468.

8. Schwartz, J.L., Yerushalmy, M., and Wilson, B. (Eds.) (1993) The Geometric Supposer: What is it a case of? Hillsdale (New Jersey): Lawrence Erlbaum Associates, Publishers. Note the focus on the classroom in the chapter by Wilson,17-22, and the ideas discussed regarding the problems of teaching in Part III (notions of promoting pupil 'enquiry' and 'thinking'). 
9. Johnson, D.C. and Samways, B. (Eds.) (1993) Informatics and Changes in Learning. Proceedings of the IFIP TC3/WG3.1/WG3.5 Open Conference, Gmunden, Austria, June 1993. Amsterdam: North Holland.

10a,b,c,d. Watson, D.M. (Ed.), (1993) The ImpacT Report: An evaluation of the impact of information technology on children's achievements in primary and secondary schools. London: King's College London (for the Department for Education).

10b. Cox, M.J. The Project Design and Method, Chapter 2, 7-25.

10c. Johnson, D.C. Summary, discussion and implications, Chapter 7, 153-166.

10d. Watson, D.M., Moore, A., and Rhodes, V. Case Studies, Chapter 4, 61-96.

11. Johnson, D.C., Cox, M.J., and Watson, D.M. (1994) Evaluating the Impact of Pupils Use of IT on Learning. Journal of Computer Assisted Learning 10 (3).

12. Johnson, D.C. (1994, in press) Logo and Angles: A Focussed Investigation with Pupils Aged 12-13. In Y.Y. Katz (Ed.) Computers in Education: Pedagogical and Psychological Implications. (IFIP).

13. Kearsley, G., Hunter, B. and Furlong, J. (1992). We Teach with Technology: New Visions for Education. Wilsonville (Oregon): Franklin, Beedle \& Associates.

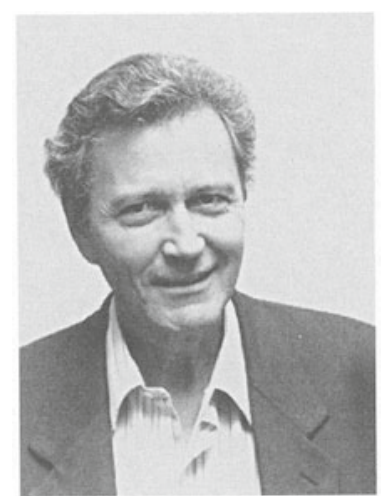

David C Johnson took up the post of Shell Professor of Mathematics Education in the University of London in 1978, following 17 years at the University of Minnesota (US). His teaching experience spans all levels from primary through university and he has been involved in school computing since 1963; activities which utilised hardware starting with mainframes in the early days, through time-share and leading on to today's micros and powerful new technologies, software and supporting equipment. He has been a member of WG3.1 (and contributor to the working group publications) since its early days 